This article was downloaded by: [CDL Journals Account]

On: 15 May 2009

Access details: Access Details: [subscription number 785022368]

Publisher Informa Healthcare

Informa Ltd Registered in England and Wales Registered Number: 1072954 Registered office: Mortimer House, 37-41 Mortimer Street, London W1T 3JH, UK

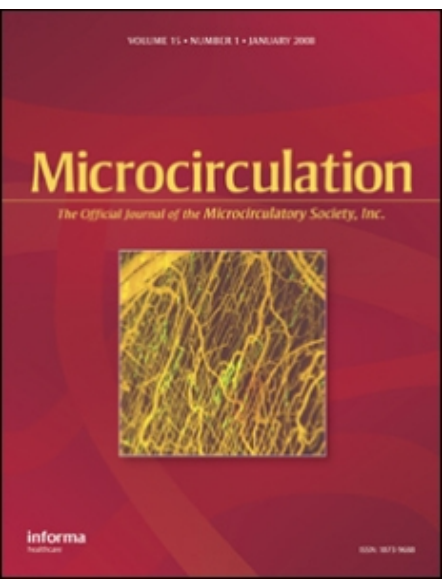

\title{
Microcirculation
}

Publication details, including instructions for authors and subscription information:

http://www.informaworld.com/smpp/title content=t713723262

\section{Event-Tracking Model of Adhesion Identifies Load-Bearing Bonds in Rolling Leukocytes}

Maria K. Pospieszalska a; Alexander Zarbock ab; John E. Pickard c; Klaus Ley a

a Division of Inflammation Biology, La Jolla Institute for Allergy and Immunology, La Jolla, California, USA ${ }^{\circ}$

Department of Anesthesiology and Intensive Care Medicine, University of Münster, Münster, Germany ${ }^{\circ}$

Robert M. Berne Cardiovascular Research Center and Department of Biomedical Engineering, University of

Virginia, Charlottesville, Virginia, USA

First Published on: 16 October 2008

To cite this Article Pospieszalska, Maria K., Zarbock, Alexander, Pickard, John E. and Ley, Klaus(2008)'Event-Tracking Model of Adhesion Identifies Load-Bearing Bonds in Rolling Leukocytes',Microcirculation, 16:2,115 - 130

To link to this Article: DOI: $10.1080 / 10739680802462792$

URL: http://dx.doi.org/10.1080/10739680802462792

\section{PLEASE SCROLL DOWN FOR ARTICLE}

\footnotetext{
Full terms and conditions of use: http://www.informaworld.com/terms-and-conditions-of-access.pdf

This article may be used for research, teaching and private study purposes. Any substantial or systematic reproduction, re-distribution, re-selling, loan or sub-licensing, systematic supply or distribution in any form to anyone is expressly forbidden.

The publisher does not give any warranty express or implied or make any representation that the contents will be complete or accurate or up to date. The accuracy of any instructions, formulae and drug doses should be independently verified with primary sources. The publisher shall not be liable for any loss, actions, claims, proceedings, demand or costs or damages whatsoever or howsoever caused arising directly or indirectly in connection with or arising out of the use of this material.
} 


\title{
Event-Tracking Model of Adhesion Identifies Load-Bearing Bonds in Rolling Leukocytes
}

\author{
MARIA K. POSPIESZALSKA, ${ }^{*}$ ALEXANDER ZARBOCK,,${ }^{\dagger}$ JOHN E. PICKARD, ${ }^{\ddagger}$ AND \\ KLAUS LEY* \\ *Division of Inflammation Biology, La Jolla Institute for Allergy and Immunology, La Jolla, \\ California, USA; ${ }^{\dagger}$ Department of Anesthesiology and Intensive Care Medicine, University of Münster, \\ Münster, Germany; ${ }^{*}$ Robert M. Berne Cardiovascular Research Center and Department of Biomedical \\ Engineering, University of Virginia, Charlottesville, Virginia, USA
}

\begin{abstract}
Objectives: P-selectin binding to P-selectin glycoprotein ligand-1 (PSGL-1) mediates leukocyte rolling under conditions of inflammation and injury. The aims of this study were to develop an efficient, high temporal resolution model for direct simulation of leukocyte rolling and conduct a study of load-bearing bonds using the model.
\end{abstract}

\begin{abstract}
Materials and Methods: A stochastic $\pi$-calculus-driven event-tracking model of adhesion (ETMA) was developed and compared with experimental data. Multiple simulations for each case were conducted to obtain high-confidence numerical characteristics of leukocyte rolling.
\end{abstract}

Results: Leukocyte rolling and the underlying P-selectin-PSGL-1 bonds were studied under low wall shear rate $\left(25-50 \mathrm{~s}^{-1}\right)$ conditions from measured parameters of leukocyte rolling and bond properties. For the first time, the location, number, lifetime, history, and kinetics of load-bearing bonds and their influence on cell rolling were identified and instantaneous cell displacements, translational and rotational velocities, and cell-substrate distances derived. The model explains the commonly observed "stop-start" type rolling behavior and reveals that a few load-bearing bonds are sufficient to support rolling, while a large number of bonds dissociate before becoming load bearing.

Conclusions: ETMA provides a method for more precise, direct simulation of leukocyte rolling at low wall shear rates and sets a foundation upon which further refinements can be introduced.

Microcirculation (2009) 16, 115-130. doi:10.1080/10739680802462792

KEY WORDS: leukocyte recruitment, neutrophils, endothelium, molecular bonds, P-selectin, PSGL-1, modeling of leukocyte rolling, pi-calculus, Gillespie's algorithm, ETMA

Leukocytes are immune cells involved in host defense. To reach sites of inflammation, leukocytes roll along the vascular endothelium (lining the blood vessel interior surface) by a series of molecular bonds between the leukocyte and the endothelium that rapidly form and dissociate. The bonds almost balance the dispersive forces exerted on the leukocyte by the flowing blood, such that each rolling leukocyte travels at a fraction of its free-flow velocity [1].

Human neutrophils, a type of leukocyte belonging to the innate immune system, have surface ruffles,

Address correspondence to Klaus Ley, Division of Inflammation Biology, La Jolla Institute for Allergy and Immunology, 9420 Athena Circle,La Jolla, CA 92037,USA. E-mail:klaus@liai.org Received 24 June 2008; accepted 9 September 2008. called microvilli (Figure 1A) [6.19], on which the sialomucin P-selectin glycoprotein ligand-1 (PSGL1 or CD162) is expressed [34]. Most leukocyte rolling is mediated by PSGL-1 binding to P-selectin (CD62P) expressed on the inflammation-activated endothelium (Figure 1B). A semianalytic computer model of rolling has been developed by Tözeren and Ley [44], which was refined by Krasik and Hammer [24]. A direct three-dimensional (3D) computer model of cell rolling, adhesive dynamics (AD), was introduced by Hammer and Apte [18], and greatly developed over time by Hammer and his coworkers $[4,7,8,25]$. They introduced a state diagram for adhesion [8], selectin, and integrin interactions $[4,25]$, as well as bound state microvillus extension and tether formation [7]. $\mathrm{Yu}$ and Shao [46] discussed possible endothelial tether formation, using a modified version of the AD model. Khismatullin and Truskey [23] and Jadhav et al. [22] 


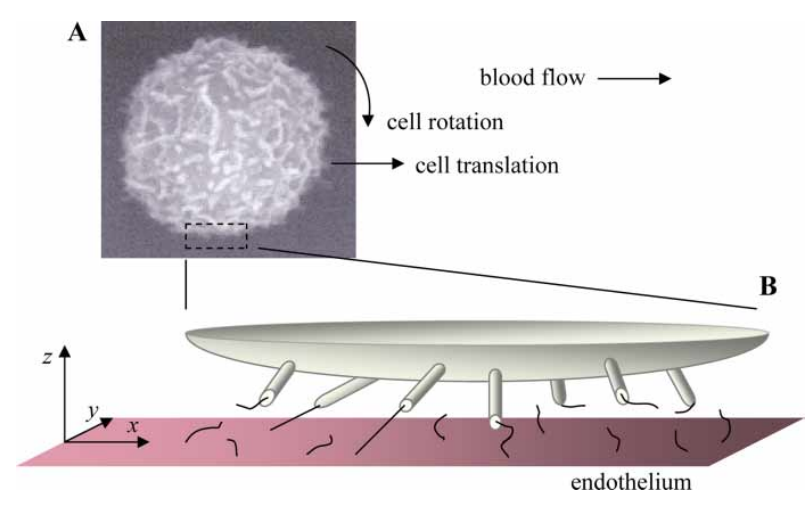

Figure 1. (A) Scanning electron micrograph of a human neutrophil (from [19], with permission). (B) Microvilli in the cell-substrate contact zone. There are two loadbearing bonds (left), and one bond bearing no load (middle). For simplicity, only one ligand per microvillus tip is shown.

modeled whole leukocyte deformation, which for cell rolling at high wall shear rates has been shown experimentally to be a highly significant factor [9]. All the above models simulate cell rolling by using fixed time intervals. An inherent limitation of such models is that the bond formation and dissociation events are implemented at the end of each time interval, and the natural sequence of those events during the time interval cannot be reconstructed. Therefore, differences in cell behavior because of particular sequences of events, cannot be identified.

Here, we develop a varying time interval, 3D, direct, stochastic $\pi$-calculus-driven event-tracking model of adhesion (ETMA) to capture the dynamics of, and make predictions about, leukocyte rolling. ETMA is the first direct rolling model that implements bond formation and dissociation events at the moment when they occur, thus simulating the natural sequence of consecutive events. Based on this model, we present a case study of human neutrophils rolling on a uniform substrate of P-selectin, such as may exist in flow chamber systems. In this study, we analyzed the formation and dissociation of bonds, their temporal and spatial distributions, and how they influence cell motion. In particular, we studied bonds that become load bearing. The load-bearing PSGL-1-P-selectin bonds are responsible for the jerky "stop-start" motion seen in rolling. There is extensive prior literature on computational $[4,7,8,18,22-25,44,46]$ and experimental studies $[6,26,27,30,31,36,43,45]$ of leukocyte rolling. However, the load-bearing bonds-that is, bonds that determine the leukocyte's rolling behavior-have not been rigorously identified and investigated. We also examined how changes in wall shear rate, Pselectin site densities, number of microvilli, and temperature influence rolling. Finally, we compared some of the predictions made by the computational model with experimental data.

\section{MATERIALS AND METHODS}

\section{Model Principles}

Event-tracking modeling of biological processes emerged as an application of Priami's [38] stochastic version of Milner's [33] $\pi$-calculus theory. The theory of Priami is suitable for a biological system in which the reaction rates for all possible events at each point in time are known. The basic idea of stochastic $\pi$-calculus is to model the dynamic behavior of the system on a race-condition basis. All the possible events at a given point in time compete for the next event by each declaring its time of occurrence (the time is selected according to the exponential distribution corresponding to the event's reaction rate), and the fastest event succeeds. The winning event is implemented, and the race starts again. The continuity of exponential distributions ensures that the probability of having two simultaneous winner events is zero. The modeling progresses by varying time steps, dictated by the time intervals between consecutive events. The ability of tracking consecutive events independent of any predefined time resolution makes the $\pi$-calculusdriven based stochastic simulation highly accurate, thus providing a better explanation of system behavior.

The idea of a stochastic $\pi$-calculus-driven modeling of cell adhesion was introduced by Lecca et al. [28]. Their model includes four different bond interactions with constant reaction rates. Since Lecca's model does not consider the cell's motion, only the instantaneous numbers of bonds were studied in [28].

\section{Model Assumptions}

The subject of our simulation was a human neutrophil rolling on P-selectin. The physiological and biophysical parameters of the process, selected based on $[2,3,6,10,11,17,29,32,34,35,37,40,42$, 47], are listed in Table 1. The neutrophil is modeled as a spherical body, with microvilli distributed 
Table 1. Model parameters for the case study.

\begin{tabular}{|c|c|c|c|}
\hline Symbol & Parameter & Value & Reference \\
\hline$r_{\mathrm{c}}$ & Cell radius $(\mu \mathrm{m})$ & 3.8 & $(40)$ \\
\hline$\rho_{\mathrm{c}}$ & Cell density $\left(\mathrm{g} / \mathrm{cm}^{3}\right)$ & 1.077 & $(47)$ \\
\hline$L_{\mathrm{m}}$ & Microvillus length (nm) & 200 & (11) \\
\hline \multirow[t]{6}{*}{$r_{\mathrm{m}}$} & Microvillus radius (nm) & 50 & (11) \\
\hline & Microvilli per cell & $941,(2,306)^{\mathrm{a}}$ & $(6)$ \\
\hline & PSGL-1 length (nm) & 50 & $(29)$ \\
\hline & PSGL-1 dimers per microvillus & $8,(4)^{a}$ & $(35)$ \\
\hline & P-selectin length (nm) & 40 & $(42)$ \\
\hline & P-selectin site density (molecules $/ \mu \mathrm{m}^{2}$ ) & $150,(200,300)^{\mathrm{a}}$ & $(34)$ \\
\hline$\mu$ & Suspending medium viscosity $(\mathrm{g} / \mathrm{cm} / \mathrm{s})$ & 0.01 & (17) \\
\hline$\rho$ & Suspending medium density $\left(\mathrm{g} / \mathrm{cm}^{3}\right)$ & 1.025 & \\
\hline$\gamma$ & Wall shear rate $\left(\mathrm{s}^{-1}\right)$ & $50,(25)^{\mathrm{a}}$ & \\
\hline$T$ & Temperature $\left({ }^{\circ} \mathbf{K}\right)$ & $290,(302.5,315)^{\mathrm{a}}$ & \\
\hline$\xi$ & Glycocalyx repulsion constant $(\mathrm{pN})$ & 10 & $(2)$ \\
\hline$\tau$ & Glycocalyx effective thickness (nm) & 15 & $(2)$ \\
\hline$\sigma$ & Bound state spring constant (dyn/cm) & 1 & $(10)$ \\
\hline$\sigma_{\mathrm{ts}}$ & Transition state spring constant $(\mathrm{dyn} / \mathrm{cm})$ & 0.98 & $(10)$ \\
\hline$\lambda$ & Equilibrium bond length (nm) & 70 & $(10,37)$ \\
\hline$k_{\mathrm{f}}^{0}$ & Equilibrium forward reaction rate $\left(\mathrm{s}^{-1}\right)$ & 1 & $(3,32)$ \\
\hline$k_{\mathrm{r}}^{0}$ & Equilibrium reverse reaction rate $\left(\mathrm{s}^{-1}\right)$ & 1 & $(3,32)$ \\
\hline
\end{tabular}

randomly on its surface. The microvilli have some flexibility (they can bend, and they can pivot at their base [41]). The PSGL-1 molecules (ligands), physiologically existing as dimers, are present on the microvilli tips [6]. The model ligands are attached at the microvilli tip centers and each represents a dimer. The endothelium is modeled as a plane (plane $x y$ in Figure 1B) expressing randomly distributed P-selectin molecules (receptors). Due to fluid flow, the neutrophil translates in the positive $x$ direction with instantaneous translational velocity, $V_{\text {tr }}$ and rotates clockwise about its center in plane $x z$ with instantaneous rotational velocity, $V_{\text {rot }}$. The rotational velocity is calculated as the product of the cell body radius and angular velocity with which the cell rolls. We neglected the effect of inertia due to the low Reynolds number [12]. To reduce the computational load, we neglected the cell's small (of an order of $\pm 1 \mu \mathrm{m}$, based on our experiments), instantaneous translations in the $y$ direction and rotations in planes other than plane $x z$. We neglected the bound state microvillus extension and tether formation. Since our analysis was limited to low wall shear rates, the microvillus extension, if modeled, would be of an order of a few nanometers and the microvillus force would be too small to form a significant tether (unpublished preliminary data from our modeling of microvillus deformability, based on Shao et al. [41]). We also did not account for whole cell deformability, which is negligible at low shear rates $[9,22]$.

At least one of the spherical or planar surfaces is assumed to have a compressible layer, called the glycocalyx, a source of a repulsive force that prevents the cell from colliding with the plane [2]. The mechanical work, $\Gamma(h)$, needed to overcome nonspecific repulsive forces to bring a unit area of cell membrane from an infinite separation from the planar surface to a separation distance of $h$ is given by [2], as shown in Equation 1:

$$
\Gamma(h)=(\xi / h) \exp (-h / \tau),
$$

where $\xi$ and $\tau$ are the repulsion constant and effective thickness of the glycocalyx, respectively. The magnitude of the repulsive force, $F_{\text {rep }}$, acting on the cell in the positive $z$ direction is obtained by integrating the derivative $-\Gamma^{\prime}(h)$ over the $x y$ plane. To accommodate freely bending microvilli, we calculated the repulsive force assuming a sphere radius of $r_{\mathrm{cm}}=r_{\mathrm{c}}+2 r_{\mathrm{m}}$, where $r_{\mathrm{c}}$ and $r_{\mathrm{m}}$ are the cell body and microvillus radii, respectively.

In the model, like in flow chamber experiments, the neutrophil is brought to the vicinity of the plane by gravitational force, where the first receptor-ligand bond formation can occur. The gravitational force is caused by a small difference in density between the neutrophil and the suspending media. In vivo, a 
similar force may be provided by margination forces [16]. The magnitude of the gravitational force, $F_{\text {grav }}$, acting on the cell in the negative $z$ direction, is calculated [18], as shown in Equation 2:

$$
F_{\text {grav }}=(4 / 3) \pi\left(r_{\mathrm{c}}+L_{\mathrm{m}}\right)^{3}\left(\rho_{\mathrm{c}}-\rho\right) g,
$$

where $L_{\mathrm{m}}$ is the microvillus length, $\rho_{\mathrm{c}}$ is the cell density, $\rho$ is the suspending medium density, and $g$. is the gravitational constant.

\section{Bond Properties}

Bonds form and dissociate, depending on the separation distance between receptors and ligands, under probabilistic rules governed by measured bond kinetics $[3,10]$. Dembo's model $[10]$ is used to calculate the forward (bond formation) and reverse (bond dissociation) reaction rates, as in $[18,22,23]$. If the separation distance, $L_{\text {sep }}$, between the microvillus tip center and the receptor base is greater than the equilibrium bond length, $\lambda$, the forward reaction rate, $k_{\mathrm{f}}$, is defined as shown in Equation 3:

$$
k_{f}=k_{\mathrm{f}}^{0} \exp \left[-\sigma_{\mathrm{ts}}\left(L_{\mathrm{sep}}-\lambda\right)^{2} /\left(2 \kappa_{\mathrm{B}} T\right)\right],
$$

and the reverse reaction rate, $k_{\mathrm{r}}$, is defined as shown in Equation 4:

$$
k_{r}=k_{\mathrm{r}}^{0} \exp \left[\left(\sigma-\sigma_{\mathrm{ts}}\right)\left(L_{\mathrm{sep}}-\lambda\right)^{2} /\left(2 \kappa_{\mathrm{B}} T\right)\right],
$$

where $k_{\mathrm{f}}^{0}$ is the equilibrium forward reaction rate, $k_{\mathrm{r}}^{0}$ is the equilibrium reverse reaction rate, $\sigma$ is the bound state spring constant, $\sigma_{\mathrm{ts}}$ is the transition state spring constant, $\kappa_{\mathrm{B}}$ is the Boltzman constant, and $T$ is the absolute temperature. If the separation distance, $L_{\text {sep }}$, between the microvillus tip center and the receptor base is smaller than or equal to the equilibrium bond length, $\lambda$, then $k_{\mathrm{f}}=k_{\mathrm{f}}^{0}$ and $k_{\mathrm{r}}=k_{\mathrm{r}}^{0}$.

Most newly created bonds bear no load initially. Some dissociate before becoming load bearing. Due to the cell's motion, bonds can become load bearing (i.e., positioned in a straight line with the microvillus and stretched beyond the equilibrium length, $\lambda$, as seen in Figure 1B), imposing on the cell forces in directions opposite to the direction of blood flow and downward toward the planar substrate, also adding torque in the $y$ direction about the cell center. The formation of load-bearing bonds slows down the cell's translational motion and can, if these bonds are sufficient in number, bring the cell to a stop until one or more load-bearing bonds break. Dissociation of load-bearing bonds speeds up the cell's translational motion, or starts the cell moving again if it was transiently at rest.

If the length of a bond is greater than $\lambda$ (i.e., the bond is load bearing at length $L_{\mathrm{sep}}$ ), the magnitude of the bond force, $F_{\mathrm{b}}=\left(F_{\mathrm{bx}}, F_{\mathrm{by}}, F_{\mathrm{bz}}\right)$, acting on the cell is calculated according to the Hookean spring model, as shown in Equation 5:

$$
F_{\mathrm{b}}=\sigma\left(L_{\mathrm{sep}}-\lambda\right),
$$

and the bond torque in the $y$ direction about the cell center is calculated as shown in Equation 6:

$$
T_{\text {by }}=\left(z_{\mathrm{m}}-z_{\mathrm{c}}\right) F_{\mathrm{bx}}-\left(x_{\mathrm{m}}-x_{\mathrm{c}}\right) F_{\mathrm{bz}},
$$

where $x_{\mathrm{c}}$ and $z_{\mathrm{c}}$ are the $x$ and $z$ coordinates of the cell center, and $x_{\mathrm{m}}$ and $z_{\mathrm{m}}$ are the corresponding coordinates of the microvillus base center. $F_{\mathrm{b}}=0$ and $T_{\mathrm{by}}=0$ for $L_{\mathrm{sep}} \leq \lambda$. Equation 5 yields values for $F_{\mathrm{bx}}$ and $F_{\mathrm{bz}}$, the bond force components in the $x$ and $z$ directions. Let Equations 7 and 8 be:

$$
\begin{aligned}
F_{\mathrm{Bx}} & =\sum F_{\mathrm{bx}}, \\
F_{\mathrm{Bz}} & =\sum F_{\mathrm{bz}},
\end{aligned}
$$

and Equation 9 be:

$$
T_{\mathrm{By}}=\sum T_{\mathrm{by}},
$$

where the summation is over all the load-bearing bonds. $F_{\mathrm{Bx}}, F_{\mathrm{Bz}}$, and $T_{\mathrm{By}}$ represent the total bond force components in the $x$ and $z$ directions and total bond torque in the $y$ direction acting on the cell, respectively.

Changes in the number of load-bearing bonds cause fluctuations in the separation distance between the cell body and the substrate and, therefore, change the size of the contact area (i.e., a circular area of the substrate where receptor-ligand bond formation can occur). In the model, instead of dealing with the constantly changing size of the contact area, we used a fixed-size area on the substrate under the cell (i.e., test area) where we check for bond formation. The test area is sufficiently large to accommodate the limiting case when the cell body would touch the substrate. The test area is larger than the true contact area at all times. This has no effect on the results of simulations, as long as the test area contains the actual contact area. The computer keeps track of all the receptors in, and ligands above, the test area. However, as the cell moves away from the substrate, more receptors near the edge of the test area do not participate in rolling, since they cannot reach any ligands. The volume 
between the test area and the cell body surface is called the contact zone.

\section{Model Algorithm}

The model tracks consecutive events and cell motion. An update of the cell position between events is performed, if needed. A time step of $10 \mu$ s for wall shear rates of $50 \mathrm{~s}^{-1}$ or lower was found to be sufficient to capture the cell motion, because using a time step of $1 \mu$ s did not significantly alter the results. If consecutive events occur very often, less than or equal to $\Delta t=10 \mu$ s apart, the modeling procedure can be described as follows. At the beginning of the simulation a spherical cell is positioned slightly below near the vertical balance point. The positions for microvillus base centers and receptor bases in the contact zone are selected randomly taking into account the microvillus radius and microvillus and receptor densities. Cell velocities, translational $V_{\mathrm{tr} 1}$, rotational $V_{\text {rot1 }}$, and vertical $V_{\text {ver1 }}$ (i.e., perpendicular to the substrate) are calculated. A competition for the first bond formation event reveals the fist time step, $\Delta t_{1} \leq \Delta t$, and points to a receptor-ligand pair that will realize the event. At the end of time step $\Delta t_{1}$, the following four steps are conducted:

Step 1. The selected event is implemented.

Step 2. Positions of the cell center, microvillus base centers, and receptor bases are updated from $\Delta t_{1}$ and $V_{\mathrm{tr} 1}, V_{\text {rot } 1}$, and $V_{\text {ver1 }}$. The new contact zone is organized (including selecting microvillus base centers and receptor bases in the leading, new part of the zone).

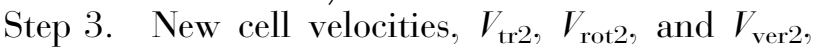
are calculated from the updated positions and bond forces acting on the cell.

Step 4. Competition for the next event determines the next time step, $\Delta t_{2} \leq \Delta t$, and points to a free (i.e., not bound) receptor-ligand pair or to a bond that will realize the event.

Repeating Steps 1-4 (using the most recently obtained time step instead of $\Delta t_{1}$, and the most recently calculated velocities instead of $V_{\text {tr1 }}, V_{\text {rot1 } 1}$, and $\left.V_{\text {ver1 }}\right)$ a number of times completes the simulation. If the time to the next event happens to be greater than $\Delta t$, then the next time step is equal to
$\Delta t$, and the simulation proceeds, as described above, with the exception of Step 1 (i.e., no event is implemented).

\section{Cell Velocities}

The cell translational velocity, $V_{\text {tr }}$, is calculated from Goldman's equations $[14,15,24]$, as shown in Equation 10:

$$
\begin{aligned}
V_{\mathrm{tr}}= & T_{\mathrm{y}}^{r^{*}}\left(F_{\mathrm{S}}+F_{\mathrm{Bx}}\right) /\left(6 \pi \mu r_{\mathrm{c}} D\right) \\
& -F_{\mathrm{x}}^{r^{*}}\left(T_{\mathrm{S}}+F_{\mathrm{By}}\right) /\left(8 \pi \mu r_{\mathrm{c}}^{2} D\right),
\end{aligned}
$$

with $D=F_{\mathrm{x}}^{\mathrm{r}^{*}} T_{\mathrm{y}}^{\mathrm{t}^{*}}-F_{\mathrm{x}}^{\mathrm{t}^{*}} T_{\mathrm{y}}^{\mathrm{r}^{*}}$, and with the shear force and torque magnitudes, as shown in Equations 11 and 12 :

$$
\begin{aligned}
& F_{\mathrm{S}}=6 \pi \gamma r_{\mathrm{c}} z_{\mathrm{c}} F_{\mathrm{x}}^{s^{*}}, \\
& T_{\mathrm{S}}=4 \pi \mu \gamma r_{\mathrm{c}}^{3} T_{\mathrm{y}}^{s^{*}},
\end{aligned}
$$

where $F_{\mathrm{Bx}}$ is given by Equation 7, $T_{\mathrm{By}}$ is given by Equation 9, $\mu$ is the suspending medium viscosity, $\gamma$ is the wall shear rate, and $F_{\mathrm{x}}^{\mathrm{t}^{*}}, F_{\mathrm{x}}^{\mathrm{r}^{* *}}, F_{\mathrm{x}}^{\mathrm{s}^{*}}, T_{\mathrm{v}}^{\mathrm{t}^{*}}, T_{\mathrm{v}}^{\mathrm{r}^{*}}$, and $T_{\mathrm{y}}^{\mathrm{s}^{* *}}$ are functions of $z_{\mathrm{c}} / r_{\mathrm{c}}$ given by Goldman et al. $[14,15]$. The cell rotational velocity, $V_{\text {rot }}$, is calculated from Goldman's equations $[14,15,24]$, as shown in Equation 13:

$$
\begin{aligned}
V_{r o t}= & F_{\mathrm{x}}^{t^{*}}\left(T_{\mathrm{S}}+F_{\mathrm{By}}\right) /\left(8 \pi \mu r_{\mathrm{c}}^{2} D\right) \\
& -T_{\mathrm{y}}^{t^{*}}\left(F_{\mathrm{S}}+F_{\mathrm{Bx}}\right) /\left(6 \pi \mu r_{\mathrm{c}} D\right),
\end{aligned}
$$

if the right-hand side of Equation 13 is less that $V_{\mathrm{tr}}$, $V_{\text {rot }}=V_{\text {tr }}$ otherwise. The cell vertical velocity, $V_{\text {ver }}$, is calculated based on Brenner [5] and Equations 1, 2, and 8, as shown in Equation 14:

$$
V_{\text {ver }}=\left(F_{\text {rep }}-F_{\text {grav }}-F_{\mathrm{Bz}}\right) /\left(6 \pi \mu r_{\mathrm{cm}} \zeta\right),
$$

where $\xi$ is the Brenner correction function of $z_{\mathrm{c}} / r_{\mathrm{cm}}$ for Stokes Law when a sphere moves near a planar surface.

\section{Competition for the Next Event}

For a free receptor-ligand pair number $n \quad(n=1$, $2, \ldots N)$ with a forward reaction rate of $k_{\mathrm{fn}}$, the time to its bond formation can be selected as shown in Equation 15:

$$
t_{\mathrm{fn}}=\left(1 / k_{\mathrm{fn}}\right) \operatorname{In}\left(1 / a_{\mathrm{n}}\right),
$$

and for a bond number $m(m=1,2, \ldots M)$ with a reverse reaction rate of $k_{\mathrm{rm}}$, the time to its dissociation can be selected as shown in Equation 16: 


$$
t_{\mathrm{rm}}=\left(1 / k_{\mathrm{rm}}\right) \operatorname{In}\left(1 / a_{\mathrm{m}}\right),
$$

where $a_{\mathrm{n}}$ and $a_{\mathrm{m}}$ are numbers selected randomly from the uniform distribution of values between 0 and $1, N=\left(N_{\text {rec }}\right)\left(N_{\text {lig }}\right)$, and $N_{\text {rec }}, N_{\text {lig }}$, and $M$ are the numbers of free receptors, free ligands, and bonds in the contact zone, respectively. Equations 15 and 16 reflect the fact that the cumulative distribution function of waiting time to an event is a uniformly distributed variable between 0 and 1 [20]. The winner is a free receptor-ligand pair or a bond that will react first, that is, in $t=\min \left\{t_{\mathrm{f} 1}, t_{\mathrm{f} 2}, \ldots t_{\mathrm{fN}}, t_{\mathrm{r} 1}\right.$, $\left.t_{\mathrm{r} 2}, \ldots t_{\mathrm{rM}}\right\}$.

If there is a set of events having the same reaction rate, Gillespie's algorithm [13] is used to reduce the computational load. For the set of $N_{\text {set }}$ possible free receptor-ligand pairs, each with its $L_{\text {sep }} \leq \lambda$, we select the time to the next bond formation for the set, as shown in Equation 17:

$$
t_{\mathrm{f}}=\left[\left(1 /\left(N_{\text {set }} k_{\mathrm{f}}^{0}\right)\right] \operatorname{In}\left(1 / a_{1}\right),\right.
$$

and point to the receptor-ligand pair number $n_{\text {set }}$ $\left(n_{\text {set }}\right.$ is a positive integer not greater than $\left.N_{\text {set }}\right)$ that will realize the event as one satisfying inequality, as shown 18:

$$
n_{\text {set }}-1<a_{2} N_{\text {set }} \leq n_{\text {set }},
$$

where $a_{1}$ and $a_{2}$ are numbers selected randomly from the uniform distribution of values between 0 and 1. Similarly, using $k_{\mathrm{r}}^{0}$ instead of $k_{\mathrm{f}}^{0}$, for the set of bonds each with its $L_{\mathrm{sep}} \leq \lambda$, we select the time to the next bond dissociation for the set and point to a bond that will realize the event. The winners from both sets compete (in the manner described at the beginning of this subsection) with the free receptorligand pairs and bonds not belonging to either set to establish the next event for the system.

\section{Other Model Properties}

In addition to tracking all free microvilli in the contact zone and all bonds inside and outside of the contact zone, ETMA tracks all free receptors in the contact zone and, therefore, imposes no restrictions concerning the angle between the bond and the substrate when the bond formation occurs (i.e., the angle can differ from 90 degrees). ETMA assigns flexibility to the microvilli and, therefore, imposes no restrictions concerning the minimum cell body to substrate separation distance (i.e., the separation distance can be less than the microvillus length and almost as small as the microvillus diameter), allowing the microvillus to bend if the space between the cell body and the substrate cannot accommodate its full length. In these cases, we assigned a value of zero for the vertical, $z$ coordinate of the microvillus tip center, accounting for microvillus bending and likely deformation.

\section{RESULTS}

\section{Case Study}

The subjects of our case study were human neutrophils rolling on a planar P-selectin substrate under the parameters listed in Table 1 . The instantaneous displacement and translational velocity, $V_{\text {tr }}$, observed at a time resolution of $10 \mu \mathrm{s}$ or better for one neutrophil in the study (also referred to as the sample cell) during the first 10.5 seconds of the simulation are shown in Figure 2A and 2B, respectively. Figure 2C gives a closer look at 0.01 seconds of the $V_{\text {tr }}$ profile. The displacement data of Figure $2 \mathrm{~A}$ filtered to 30 frames per second, a time resolution commonly used in experiments, yield a translational velocity trace similar in character to experimental results (Figure 2D and 2E). The neutrophil's average translational velocity, under the conditions investigated, is $3.18 \mu \mathrm{m} / \mathrm{s}$, which corresponds well with experimental data. An initial period of time during which the cell approaches the substrate for the first time (in this case, a period of 0.1 seconds) is excluded from the calculations of numerical averages.

The scatter plot in Figure 3A shows the neutrophil's instantaneous rotational velocity, $V_{\text {rot }}$, versus its translational, $V_{\text {tr. }}$. The changes in $V_{\text {rot }}$ are seen as individual traces when $V_{\mathrm{rot}}<V_{\mathrm{tr}}$. Otherwise, they all fall on the $V_{\text {rot }}=V_{\text {tr }}$ line. The average value of ratio $V_{\text {rot }} / V_{\text {tr }}$ computed for the neutrophil's rolling is 0.9 . A slip occurs (slip velocity, $V_{\text {slip }}=V_{\text {tr }}-V_{\text {rot }}$ ) when there are no load-bearing bonds or the total load of the load-bearing bonds is small. A slip velocity of $10 \%$ is within the range of experimental results [44]. The neutrophil's instantaneous velocity in the $z$ direction is shown in Figure 3B and 3C. After the initial 0.1 seconds, the cell's body rolls on the substrate at an average separation distance of 164 $\mathrm{nm}$ (Figure 3D). This is less than the microvillus length, so that some of the microvilli must bend while under the neutrophil.

On average, the rolling neutrophil forms about 18 bonds with the substrate, which is less than predicted by very early modeling and experimental 

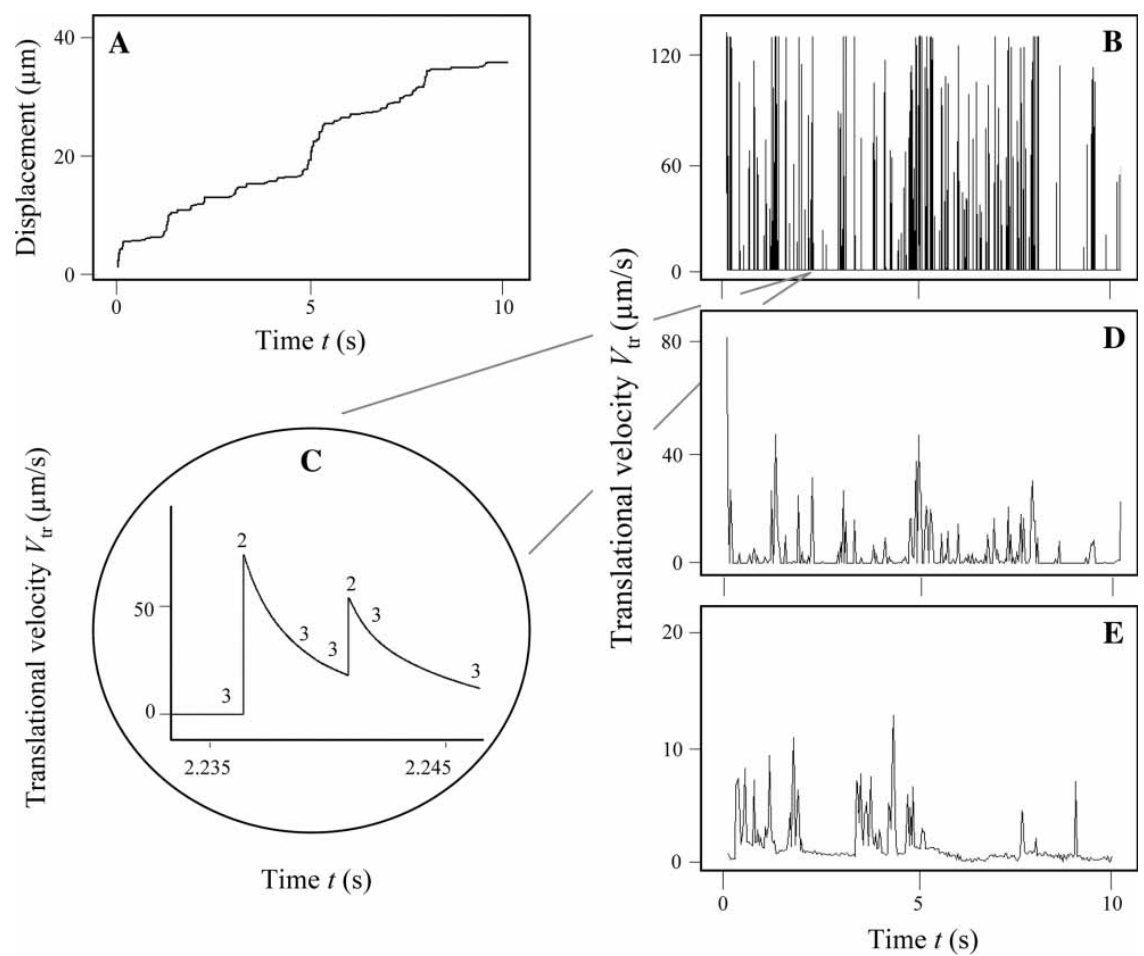

Figure 2. Displacement $(\mathbf{A})$ and translational velocity, $V_{\text {tr }},(\mathbf{B})$ for the sample cell discussed in the case study (parameters as in Table 1). The profiles in $\mathbf{A}$ and $\mathbf{B}$ are based on 1,216,520 data points each (time resolution better than $10 \mu \mathrm{s}$ ). The first load-bearing bond appears near $t=0.0091 \mathrm{~s}$, and the first, very short pause in the cell's motion occurs near $t=0.026 \mathrm{~s}$. (C) High-resolution of a 0.01 -second segment of data in B. The numbers along the curve are the instantaneous numbers of load-bearing bonds. (D) Translational velocity for the same cell calculated from a subset of the displacement data in A recorded every 1/30 s. (E) Translational velocity of a human neutrophil rolling in our parallel-plate flow chamber experiment on roughly 150 molecules $/ \mu \mathrm{m}^{2}$ of P-selectin at a wall shear rate of $50 \mathrm{~s}-1$, recorded at 30 frames/s.

results [21] (Figure 4A, black curve). Fluctuations in the number of bonds are consistent with the cell pause and movement stages of rolling. During a pause the number of bonds generally increases, and it generally decreases during acceleration. On average, only four bonds are load bearing (Figure 4A, red curve). A sudden, large increase in the number of load-bearing bonds, followed by a slower, steptype decrease, is a common pattern (Figure 4B). A comparison with the $V_{\text {tr }}$ profile reveals that sudden large increases in the number of load-bearing bonds initiate pauses in cell motion (Figure 4B).

In order to understand the nature of patterns such as those in Figure 4B, we analyzed in detail the sudden increase (marked with an asterisk in Figure $4 \mathrm{~B}$ ) in the number of load-bearing bonds, from one loadbearing bond (of 24 existing bonds) at time $t_{1}=$ $6.0528 \mathrm{~s}$ to seven load-bearing bonds (of 24 existing bonds) at time $t_{2}=6.0536 \mathrm{~s}$. Figure $5 \mathrm{~A}$ and $5 \mathrm{~B}$ show the positions of the bond-receptor bases (i.e., places where the receptors are attached to the substrate) at times $t_{1}$ and $t_{2}$, respectively. The red circles indicate the receptor base positions of load-bearing bonds, while the gray circles indicate the receptor base positions of other existing bonds. In $0.8 \mathrm{~ms}$, the one load-bearing bond in Figure $5 \mathrm{~A}$ is joined by six newly load-bearing bonds in Figure 5B. There is one four-bond cluster fully load-bearing and two twobond partially load-bearing clusters (all three marked by solid ovals in Figure 5B, each containing at least one red circle), with each cluster corresponding to a different microvillus. In addition, there is one four-microvillus cluster (marked by a dashed oval in Figure 5B) that is partially load bearing. Among the bonds that do not bear any load, there are one four-bond, two three-bond, and two twobond clusters (all five marked by solid ovals in Figure 5B, each containing gray circles only). Our simulation shows that the simultaneous existence of several bonds involving the same microvillus is typical, and that microvilli can be located close to 

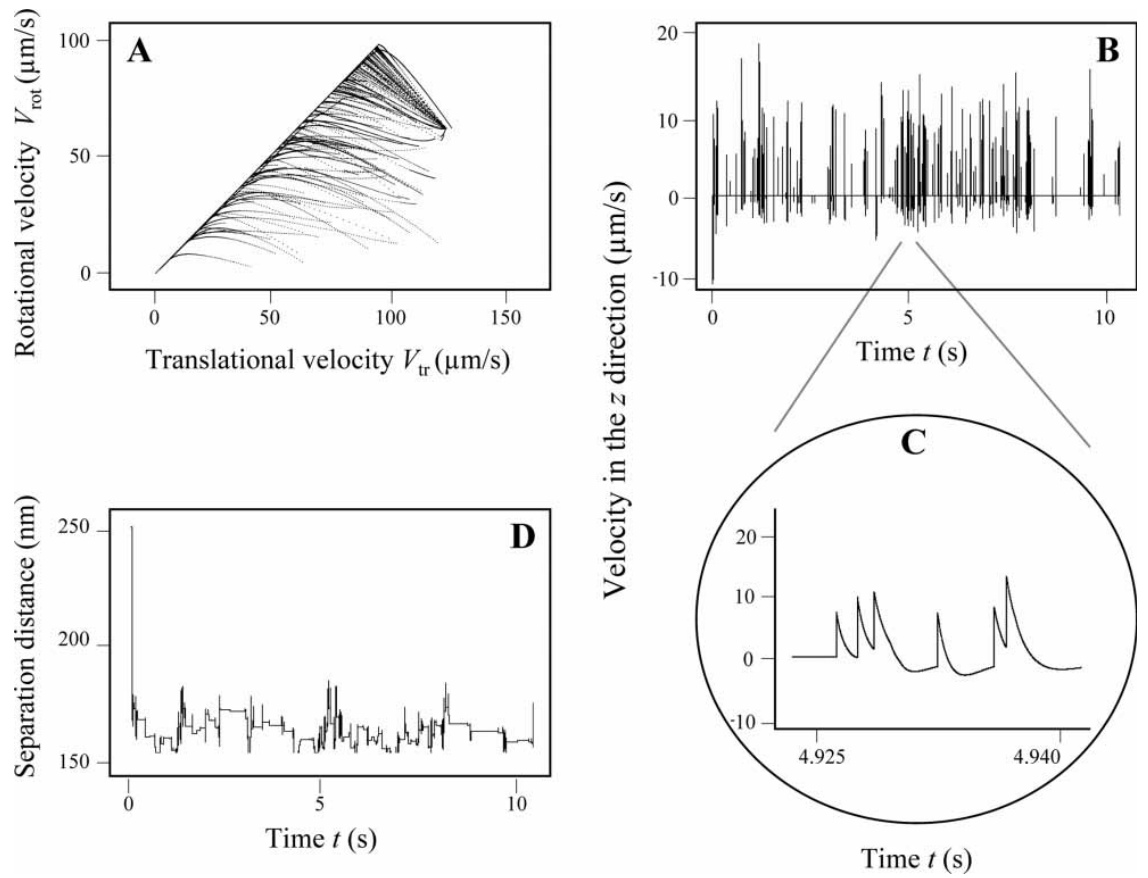

Figure 3. (A) Scatter plot of rotational velocity, $V_{\text {rot, }}$, versus translational velocity, $V_{\text {tr. }}($ B) Velocity in the $z$ direction, perpendicular to the substrate. A positive velocity indicates that the cell is moving away from the substrate. (C) High resolution of a 0.015-second segment of data in B. (D) Cell body to substrate separation distance. The diagrams are for the sample cell discussed in Figure 2A-D.

each other. As a result, when a bond becomes load bearing, all the other bonds of its cluster become load bearing approximately at the same time, causing a sudden increase in the number of loadbearing bonds. This drastically slows down the cell motion and often brings the cell to a temporary rest.

Almost all the load-bearing bonds reside in a halfmoon shape on the neutrophil's trailing side (Figure $5 \mathrm{~A}-5 \mathrm{D}$ ). Figure $6 \mathrm{~A}$ is a cumulative map for a sample of all the 397 load-bearing bonds observed during the cell's rolling over 14 seconds. Each bond is represented by two asterisks, one red and one black, both with the same $y$ coordinate. The red asterisk marks the position of the receptor base with respect to the cell center when the bond becomes load bearing (i.e., load position), and the black asterisk marks the position of the receptor base when the bond dissociates (i.e., break position). In rare cases (marked with arrows in Figure 6A), load-bearing bonds are found on the leading side and, consequently, undergo a compression period of reduced load due to the cell translation and rotation. The bond marked with a black arrow dissociates immediately. The other two bonds marked with arrows undergo load reduction (down to $0 \mathrm{pN}$ for the one marked with the green arrow) and then load increases before they dissociate. Each load and break position is described by its polar coordinates, radius $r$ and angle $\varphi(-\pi<\varphi \leq \pi)$, as seen in Figure $6 \mathrm{~A}$. Each of the two sets of positions has a relatively smooth upper boundary (i.e., there are almost no positions to the left of the boundary). A larger sample of 4,509 bonds (based on simulations for 10 different cells with a total rolling time of 143 seconds) yields $95 \%$ confidence intervals (CIs) of $0.856 \pm 0.003$ and $1.052 \pm 0.003 \mu \mathrm{m}$ for the mean radius $r$ of the load and break positions, respectively. The middle $95 \%$ of the sample load positions lie inside the 132-degree (i.e., $|\varphi|=66$ degree) pie, and the upper boundary for those positions is approximately circular at $r=0.95 \mu \mathrm{m}$. The $r$ value was computed by dividing the 132-degree pie into 3 degree slices, for a total of 44 slices. For each slice, the maximum observed radius was found and the mean value for the sample of 44 maximum radii was computed. Similarly, the middle $95 \%$ of the sample break positions lie in the 96-degree (i.e., $|\varphi|=48$ degree) pie, and the upper boundary for those positions is approximately circular at $r=1.17 \mu \mathrm{m}$. Angle $\varphi$ is between \pm 10 or \pm 20 degrees for 18 and $36 \%$ of load positions and 23 and $46 \%$ of break positions, respectively. Figure $6 \mathrm{~B}-6 \mathrm{E}$ describe the 


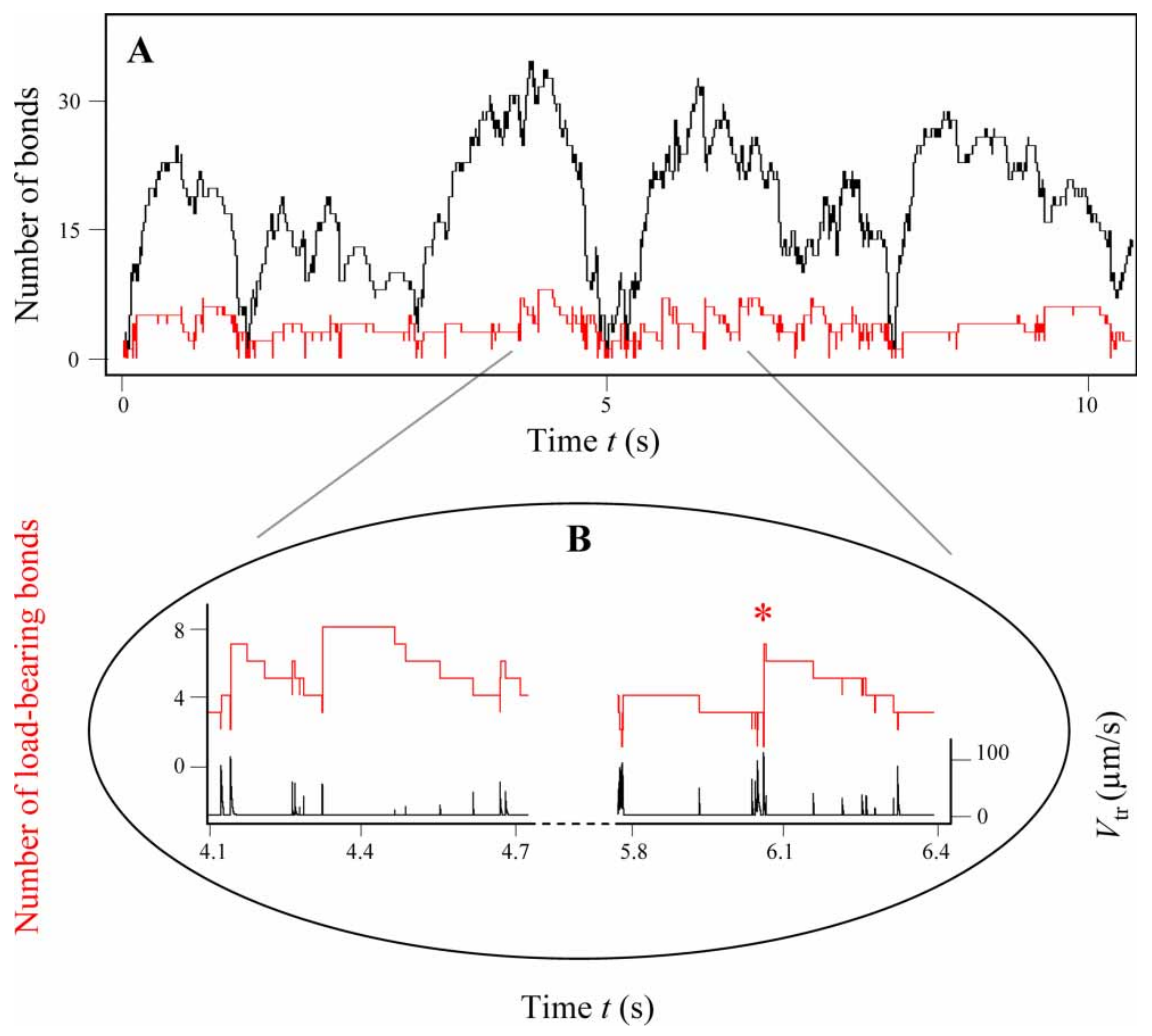

Figure 4. (A) Total number of bonds (black curve) and load-bearing bonds (red curve) for the sample cell discussed in Figure 2A-D and 3. (B) High resolution of two 0.6-second segments of load-bearing bond data in A (red curve, left axis) and corresponding translational velocity profile (black curve, right axis). The asterisk marks the sudden increase in the number of load-bearing bonds analyzed in detail.

sample distributions of radius $r$ and angle $\varphi$ for the load (red curves) and break (black curves) positions of the cell's trailing side.

A study of the bond lifetimes revealed additional details about the nature of patterns similar to those in Figure 4B. Figure 7A presents the history of the seven bonds shown in Figure 5B as load-bearing at $t=6.0528 \mathrm{~s}$. Each bond is represented by a horizontal segment with three points. The left point marks the time when the bond is formed, the middle point marks the time when the bond becomes load bearing, and the right point marks the time when the bond dissociates. The red segment illustrates the period of time when the bond is load bearing. The bonds are formed at different times, but all become load bearing approximately at the same time. Therefore, the increase in the number of loadbearing bonds occurs suddenly. Bonds dissociate at different times. Therefore, the decrease in the number of load-bearing bonds occurs gradually, if no new load-bearing bonds are involved in the process. The above findings explain the pattern seen in Figure 4B. Our study shows that while the bond formation and dissociation events are governed by probabilistic rules (Equations 3, 4, 15, and 16), the dynamics of bond loading are strongly influenced by the instantaneous number of load-bearing bond clusters (because of the concentration of ligands at the microvilli tips [6] and because of randomly occurring microvillus clusters). Irregular fluctuations in the number of these clusters cause the commonly observed cell "stop-start" rolling behavior.

A total of 6.336 bonds were formed during our simulation for the 10 cells, with a total rolling time of 143 seconds. The percent histogram of the lifetimes for the bonds formed is given in Figure 7B. Of the 6.336 bonds formed, 4.509 lasted 


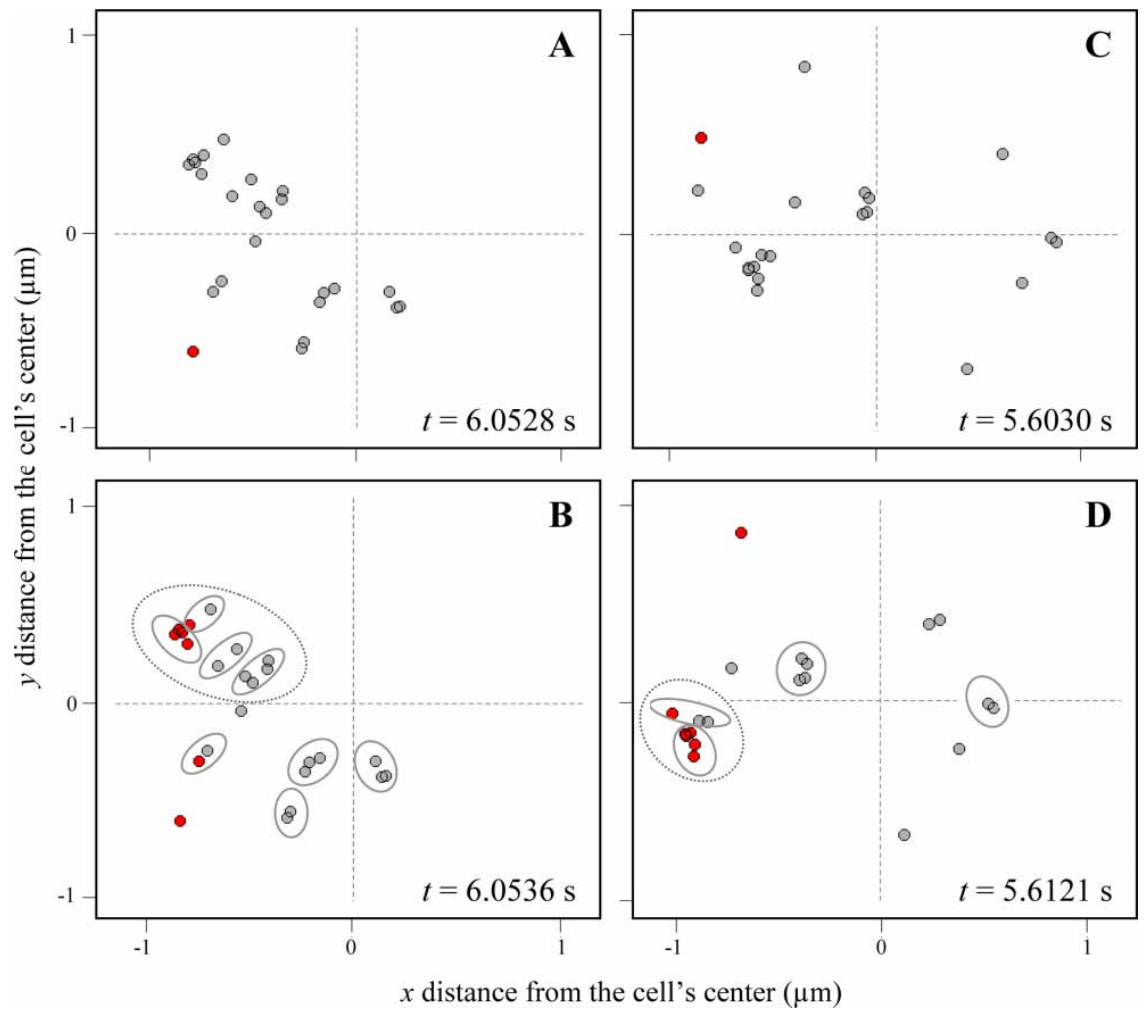

Figure 5. Distribution of the locations of bond receptor bases (circles) at $t=6.0528 \mathrm{~s}(\mathbf{A})$ and $t=6.0536 \mathrm{~s}(\mathbf{B})$, and also at $t=5.603 \mathrm{~s}(\mathbf{C})$ and $t=5.6121 \mathrm{~s}(\mathbf{D})$, for the sample cell discussed in Figure 2A-D, 3, and 4. The load-bearing bond bases are marked with red circles. In $\mathbf{B}$ and $\mathbf{D}$, solid ovals indicate groups of bonds located on the same microvillus, while dashed ovals indicate partially load-bearing microvillus clusters.

sufficiently long to become load bearing. The histogram of the durations of the load-bearing stage for these bonds is given in Figure 7C.

\section{Numerical Descriptions of Cell Rolling}

In order to obtain high-confidence numerical characteristics of the cell-rolling process for the set of parameters, assumed for the case study, we conducted 20 simulations for 20 different cells. Each simulation generated five to six seconds of cell rolling. The sample of 20 values was tested for normality by using a normal probability plot procedure. Our samples represent approximately normal distributions, resulting in $95 \%$ CIs of $3.42 \pm 0.51$ $\mu \mathrm{m} / \mathrm{s}$ for the mean translational velocity, $164.5 \pm 0.5$ $\mathrm{nm}$ for the mean cell body to substrate separation distance, $16.6 \pm 0.8$ for the mean total number of bonds, $3.7 \pm 0.2$ for the mean total number of loadbearing bonds, $0.39 \pm 0.03 \mathrm{~s}$ for the mean bond lifetime, $69 \pm 2.5 \%$ for the mean fraction of bonds that become load bearing, and $0.13 \pm 0.01 \mathrm{~s}$ for the mean duration of the load-bearing stage of those bonds.

\section{Sensitivity to Parameters}

We also considered other scenarios that could change the effectiveness of cell rolling. To investigate how the translational velocity depends on physiological parameters, we studied cell rolling at lower wall shear rates of $25 \mathrm{~s}^{-1}$, higher P-selectin site densities of 200 molecules $/ \mu \mathrm{m}^{2}$ and 300 molecules $/ \mu \mathrm{m}^{2}$, and higher temperatures of 302.5 and $315^{\circ} \mathrm{K}$. For each new parameter, we performed 10 simulations, conducted and analyzed as described above, while all other parameters were the same as in the case study. The cell mean translational velocity, as a function of wall shear rate and as a function of P-selectin density, is given in Figure 7D, 

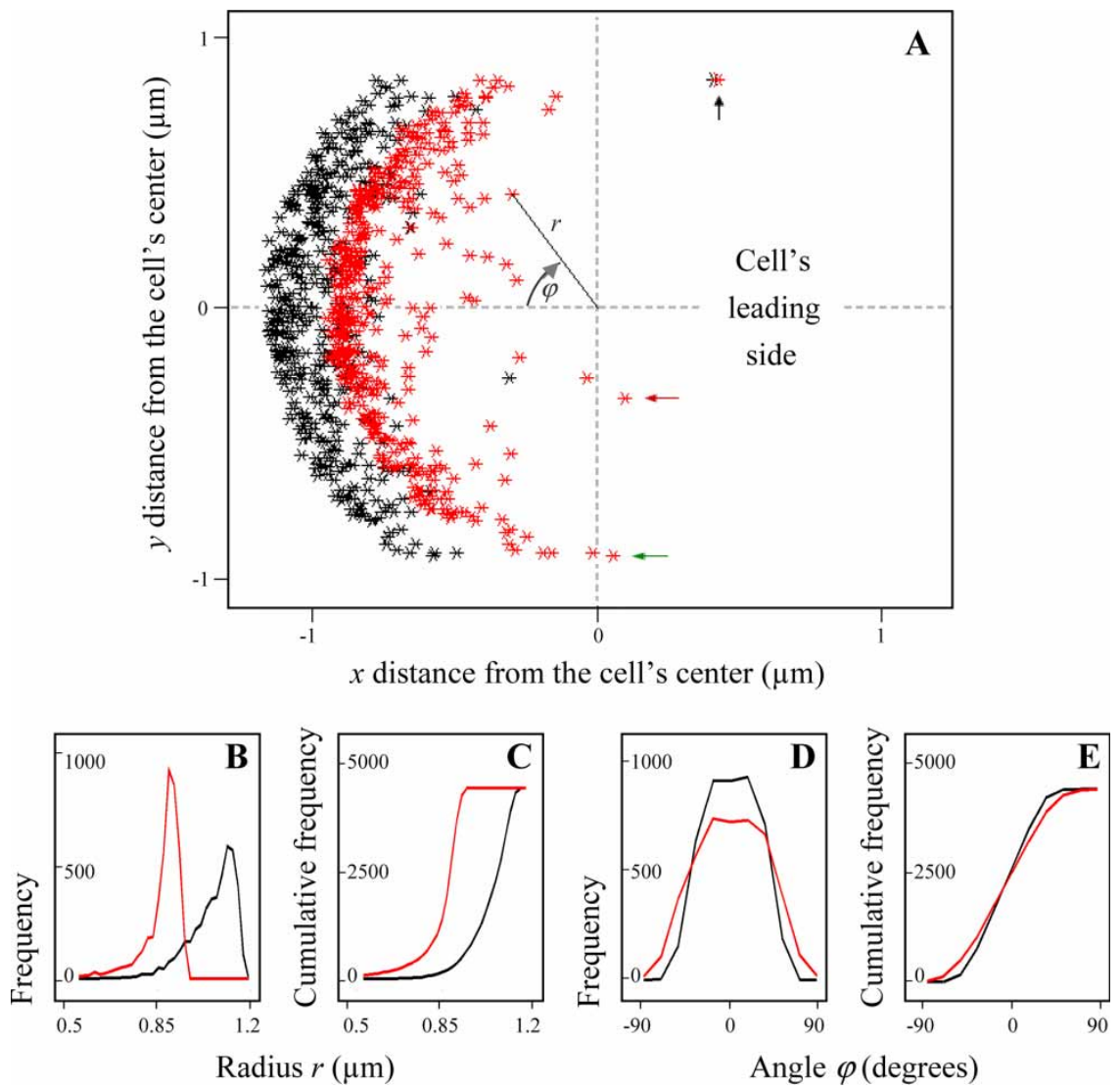

Figure 6. (A) Cumulative map of the load (red asterisks) and break (black asterisks) positions for 397 load-bearing bonds observed during a 14 seconds of rolling of the sample cell discussed in Figure 2A-D and 3-5. Rare bonds (marked with arrows) formed on the leading side undergo load reduction (down to $0 \mathrm{pN}$ in case of the green arrow) and then they dissociate (black arrow) or undergo load increase before they dissociate (green and red arrows). All other bonds experience load increase over time. Radius $r$ and angle $\varphi$ are position polar coordinates. (B)-(E) Frequency and cumulative frequency of radius $r$ and angle $\varphi$ for a sample of 4,459 load-bearing bonds observed on the cell's trailing side during simulations of 10 different cells rolling for a total of 143 seconds. The red curves describe the load positions, and the black curves describe the corresponding break positions for the sample bonds. The diagrams are based on 61bar (radius) and 10-bar (angle) histograms where the curve connects the top centers of the bars.

together with $95 \%$ CIs. As the wall shear rate decreases or the P-selectin density increases, the cell mean translational velocity decreases, as $\mathrm{ex}^{-}$ pected [27]. The decrease is statistically highly significant. Two-sample Student's $t$-tests applied to the pairs of samples involved yield two $P$-values less than 0.0001 and two others of 0.001 and 0.009 . The same types of tests revealed that the cell mean translational velocity is not sensitive to changes in temperature in a range of 290 to $315^{\circ} \mathrm{K}$ (data not shown). This leads to the conclusion that human neutrophil rolling at room temperature on $\mathrm{P}$-selectin in vitro is similar to rolling at body temperature.
We also increased the number of microvilli per cell $(2,306)$ and reduced the number of PSGL-1 dimers per microvillus (4), keeping the other parameters the same as in the case study. On average, based on 10 cell samples, the rolling neutrophil forms more bonds with the substrate (31), but only a few bonds are needed to maintain rolling (5). 95\% CIs are $1.49 \pm 0.13 \mu \mathrm{m} / \mathrm{s}$ for the mean translational velocity, $159 \pm 1.05 \mathrm{~nm}$ for the mean cell body to substrate separation distance, $31 \pm 1.8$ for the mean total number of bonds, $5.3 \pm 0.23$ for the mean total number of load-bearing bonds, $0.53 \pm 0.04 \mathrm{~s}$ for the mean bond lifetime, $56 \pm 2.54 \%$ for the mean 

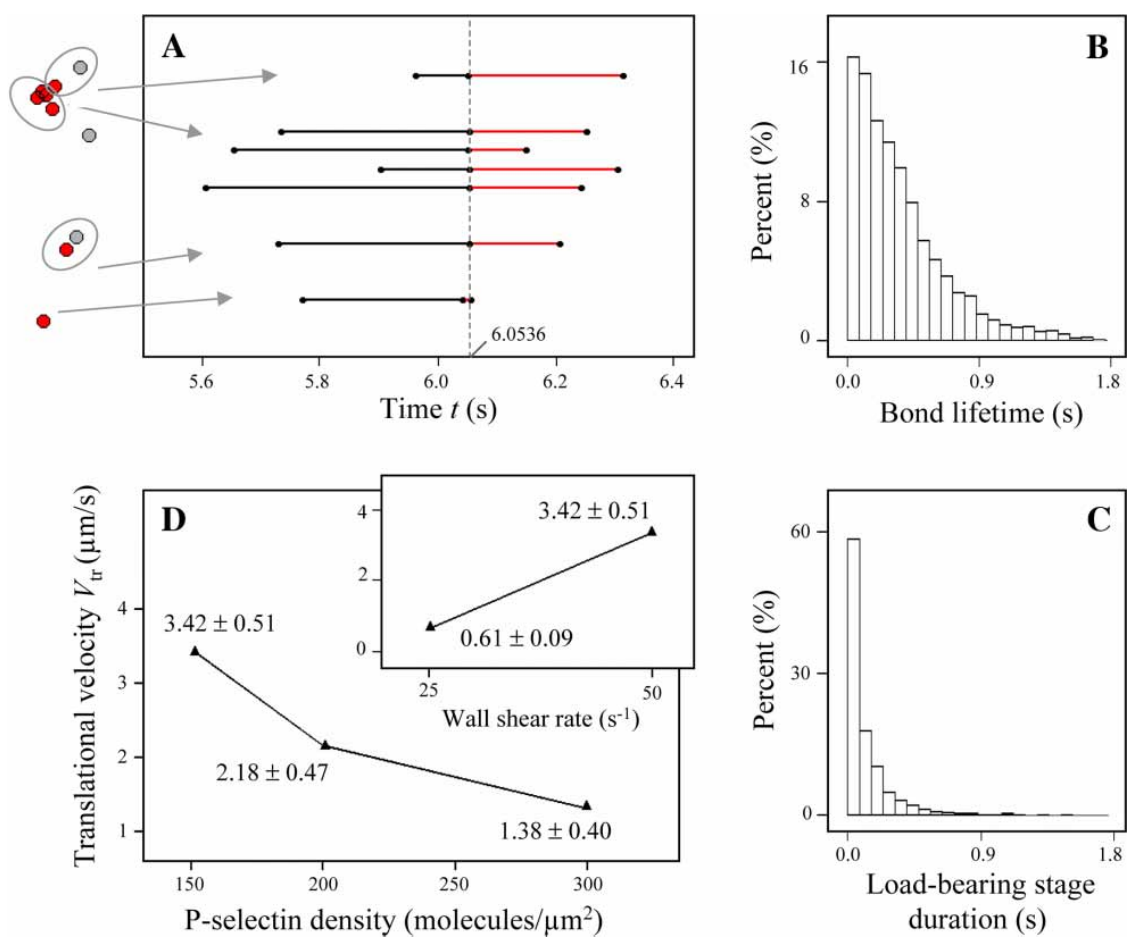

Figure 7. (A) Lifetime of seven load-bearing bonds at $t=6.0636 \mathrm{~s}$ (same bonds as in Figure 5B). Each bond is represented by a black segment (no load-time period) and a red segment (load-time period). Histograms of the lifetimes of the bonds formed (B), and of the corresponding load-bearing stage durations (never-loaded bonds excluded) (C), both based on simulations of the 10 cells rolling for a total of 143 seconds discussed in Figure 6B-E. (D) Translational velocity, $V_{\mathrm{tr}}$, as a function of $\mathrm{P}$-selectin density and wall shear rate (insert). All parameters, except the independent variable, are as in the case study (Table 1). The 95\% confidence intervals for the cell mean translational velocity are given in $\mu \mathrm{m} / \mathrm{s}$. Each interval is based on simulations of at least 10 different cells rolling for five to six seconds each.

fraction of bonds that become load bearing, and $0.17 \pm 0.01 \mathrm{~s}$ for the mean duration of the loadbearing stage of those bonds. The bond formation, loading, and dissociation dynamics are the same as discussed earlier, with bond clustering (also due to the concentration of PSGL-1 molecules on the microvilli tips and the microvillus clusters) shaping the cell motion. Decreasing the wall shear rate to 25 $\mathrm{s}^{-1}$ reduces the mean translational velocity of $1.49 \pm 0.13$ to $0.44 \pm 0.05 \mu \mathrm{m} / \mathrm{s}(95 \% \mathrm{CI})$. Increasing the P-selectin density to 300 molecules $/ \mu \mathrm{m}^{2}$ reduces the mean translational velocity to $0.78 \pm$ $0.07 \mu \mathrm{m} / \mathrm{s}(95 \% \mathrm{CI})$. Both decreases in the mean translational velocity are statistically highly significant. Two-sample Student's $t$-tests yield $P$-values less than 0.0001 .

\section{Comparison to Experiment}

There is a limited number of experiments reported on human neutrophils rolling in flow chambers on
P-selectin at low shear rates (our own unpublished data, 2007; Lawrence and Springer [27], Yago et al., [45]), with [27] being the most detailed. Experimental results can vary due to differences in the neutrophil isolation and substrate preparation methods. We did not adjust any parameters to match experimental data. For each case of shear rate and $\mathrm{P}$-selectin site density values discussed below, all other parameters are as in the case study.

Figure 2E shows the translational velocity for a human neutrophil rolling on P-selectin in our parallel-plate flow chamber experiment on roughly 150 molecules $/ \mu \mathrm{m}^{2}$ of $\mathrm{P}$-selectin at a wall shear rate of $50 \mathrm{~s}^{-1}$ (as in the case study). The cell was tracked with an active-contour-based automatic image-processing algorithm at 30 frames per second [39]. The neutrophil average translational velocity was measured at $1.52 \mu \mathrm{m} / \mathrm{s}$, which falls into the slowest $5 \%$ of the model cells.

Our simulations, 10 for each case, at a wall shear rate of $\gamma=50 \mathrm{~s}^{-1}$, yield $95 \%$ CIs for neutrophil 
mean translational velocities of $3.42 \pm 0.51,2.18 \pm$ 0.47 , and $1.38+0.4 \mu \mathrm{m} / \mathrm{s}$ for P-selectin site densities of 150,200 , and 300 molecules $/ \mu \mathrm{m}^{2}$, respectively. There is good agreement between these results and the measurements of [27]. Based on [27], the mean translational velocities fall between 2.47 and $4.25 \mu \mathrm{m} / \mathrm{s}$ for a P-selectin density of 150 molecules $/ \mu \mathrm{m}^{2}$ and between 1.1 and $2.47 \mu \mathrm{m} / \mathrm{s}$ for a P-selectin density of 300 molecules $/ \mu \mathrm{m}^{2}$. For a Pselectin density of 200 molecules $/ \mu \mathrm{m}^{2}$, a case described in more detail in [27], an interval for the mean translational velocity estimated from [27] is $2.47 \pm 0.59 \mu \mathrm{m} / \mathrm{s}$, mean \pm standard error of the mean (SEM) and includes our model result of 2.18 $\mu \mathrm{m} / \mathrm{s}$ for this case. The interval is based on all cells that rolled in the time period of observation (approximately $92 \%$ of all cells observed).

At $\gamma=36 \mathrm{~s}^{-1}, 95 \%$ CIs for neutrophil mean translational velocities are $1.23 \pm 0.16,0.97 \pm 0.16$, and $0.64 \pm 0.1 \mu \mathrm{m} / \mathrm{s}$ for P-selectin site densities of 150,200 , and 300 molecules $/ \mu \mathrm{m}^{2}$, respectively. The mean values are slightly lower that those measured by [27]. Results of [27] predict the mean translational velocities falling between 1.9 and $3.6 \mu \mathrm{m} / \mathrm{s}$ for a P-selectin density of 150 molecules $/ \mu \mathrm{m}^{2}$ and between 1 and $1.9 \mu \mathrm{m} / \mathrm{s}$ for a P-selectin density of 300 molecules $/ \mu \mathrm{m}^{2}$. For a P-selectin density of 200 molecules $/ \mu \mathrm{m}^{2}$, a case described in detail in [27], the interval given in [27] is $1.9 \pm 0.7 \mu \mathrm{m} / \mathrm{s}$ mean \pm SEM. The interval is based on all cells that rolled in the time period of observation $(89 \%$ of all cells observed).

There is good agreement between our results and the measurements of [45]. For a P-selectin site density of 145 molecules $/ \mu \mathrm{m}^{2}$, a case discussed in [45], five simulations with $\gamma=50 \mathrm{~s}^{-1}$ yield a sample mean translational velocity of $3.78 \mu \mathrm{m} / \mathrm{s}$ [sample standard deviation $(\mathrm{SD})=0.59 \mu \mathrm{m} / \mathrm{s}$ ], while the corresponding data of [45], based on five experiments, are 3.8 $\mu \mathrm{m} / \mathrm{s}(\mathrm{SD}=0.4 \mu \mathrm{m} / \mathrm{s})$. At elevated wall shear rates, cells modeled as rigid spheres with nonextendable microvilli roll faster than experimental cells, with average translational velocities of $68,90,95$, and $97 \%$ of free stream velocity for wall shear rates of $75,100,150$, and $200 \mathrm{~s}^{-1}$, respectively.

\section{DISCUSSION}

In spite of tremendous progress in measuring the molecular and cellular processes involved in inflammation, the dynamics of leukocyte recruitment cannot be fully understood without quantitative modeling. ETMA allowed for a comprehensive study of the subgroup of bonds, which at some point in time, become load bearing and, therefore, determine the cell's rolling, which has not been rigorously investigated before. Although it has been surmised that load-bearing bonds must be near the trailing edge, no formal treatment of their exact location can be found in the literature. Caputo and Hammer [?] show a cartoon of the location of load-bearing bonds in their Figure 2, but do not provide any experimental or modeling evidence. Here, we identify the location, number, lifetime, history, and kinetics of load-bearing bonds and make new predictions concerning their influence on cell rolling. We also make new predictions concerning the cell body to substrate separation distance, which might become accessible to new experimental techniques in the future.

Surprisingly, very few load-bearing bonds are needed to maintain rolling, and about $30 \%$ of bonds are wasted, since they don't last long enough to become load bearing. We observe that in addition to bond clusters due to the concentration of PSGL-1 molecules on the microvilli tips, large microvillus clusters can occur, as illustrated in Figure 5B and 5D. That is consistent with the scanning electron micrograph of the cell's surface shown in Figure 1A. Since the loading events in a bond cluster were found to rapidly encompass all available bonds, we conclude that the number of bond clusters approaching the loading zone determines how "jerky" the cell rolling will be. Our $\pi$-calculus-driven ETMA is an alternative to $\mathrm{AD}$ of Hammer and Apte [18], the only published direct model of leukocyte rolling. The physics in ETMA are standard, based on Goldman-Cox-Brenner theory, and are used as in [44] and AD. However, the modeling method is quite different from that used in $\mathrm{AD}$.

- ETMA progresses by varying time steps driven by bond events, while AD progresses by fixed, predefined time steps.

- ETMA implements each bond event when it occurs, while AD implements each bond event at the end of the corresponding time step.

- The occurrence of an event immediately changes the dynamic state of the system and has direct influence for the future evolution of the system. ETMA gives each bond event a chance to have an individual impact by implementing the events in their natural sequence, while $\mathrm{AD}$ implements 
bond events in the same time step as coincidental, when they are actually sequential.

- ETMA allows a bond to form and break within any predefined time interval, such as the $\mathrm{AD}$ 's time step, while AD doesn't allow for a bond to form and break within the same time step. The selection of events in AD depends exclusively on the state of the system at the beginning of the time step. Consequently, two selected events, implemented at the end of a time step as coincidental, cannot involve the same receptor-ligand pair.

- ETMA provides high temporal resolution of bond events, while $\mathrm{AD}$ delays bond events and may lump them when longer time steps are used.

- ETMA is computationally efficient, minimizing the number of system updates for maximum accuracy of event implementation, while AD becomes computationally costly when short time steps are used in an attempt to improve accuracy.

ETMA's event implementation accuracy and computational efficiency constitute an advantage over the fixed time step of the AD model. No matter how small the fixed time step, the probabilistic nature of bond formation and dissociation events may yield two or more bond events for some time steps. Even AD simulations using a fixed time step of $0.1 \mu$ s [?] may not be sufficient, since in our case study the shortest time separation between consecutive events was $0.0137 \mu \mathrm{s}$. ETMA implements bond events accurately, as they occur, while AD implements them in groups at the ends of corresponding time steps, which only approximates the true dynamics of the system. The AD model is not capable of achieving the level of temporal resolution of bond events offered by ETMA, but can improve its accuracy by shortening its fixed time step to lower the probability of more than one bond event in each time step. However, that decreases the computational efficiency by generating many "empty" time steps where no bond events occur, which have to be processed at a computational cost. In ETMA, the system updates occur when the bond events occur with additional updates in between, only if needed to keep track of cell motion.

\section{CONCLUSIONS}

ETMA, as presented here, has certain limitations. Currently, and like other models, we cannot model leukocyte rolling at high wall shear rates. This is most likely due to the model's inability to account for whole cell and bound state microvillus deformations, which are significant in these cases. Future refinements of ETMA will be needed to accommodate these cases. Despite its limitations, ETMA provides a method for a highly precise, direct simulation of leukocyte rolling. ETMA sets a foundation upon which further refinements can be introduced that will allow the modeling of leukocyte rolling at high wall shear rates, with different and multiple ligands, and for different cell types.

\section{ACKNOWLEDGEMENTS}

This work was supported, in part, by the National Institutes of Health (grant \#2R01EB002185) and Deutsche Forschungsgemeinschaft to A.Z. (grant \#AZ 428/2-1).

The statistical tests were conducted by using the Statistical Analysis System (SAS Institute Inc., Cary, North Carolina, USA)

The authors thank E. R. Damiano, W. H. Guilford, M. B. Lawrence, and B. J. Schmidt for their helpful discussions.

\section{REFERENCES}

1. Atherton A, Born GVR. (1973). Relationship between the velocity of rolling granulocytes and that of the blood flow in venules. J Physiol 233:157-165.

2. Bell GI, Dembo M, Bongrand P. (1984). Cell adhesion. Competition between nonspecific repulsion and specific bonding. Biophys J 45:1051-1064.

3. Bell GI. (1978). Models for the specific adhesion of cells to cells. Science 200:618-627.

4. Bhatia SK, King MR, Hammer DA. (2003). The state diagram for cell adhesion mediated by two receptors. Biophys J 84:2671-2690.

5. Brenner H. (1961). The slow motion of a sphere through a viscous fluid towards a plane surface. Chem Eng Sci 16:242-251.

6. Bruehl RE, Springer TA, Bainton DF. (1996). Quantitation of L-selectin distribution on human leukocyte microvilli by immunogold labeling and electron microscopy. J Histochem Cytochem 44:835-844.

7. Caputo KE, Hammer DA. (2005). Effect of microvillus deformability on leukocyte adhesion explored using adhesive dynamics simulations. Biophys J 89:187-200.

8. Chang KC, Tees DFJ, Hammer DA. (2000). The state diagram for cell adhesion under flow: leukocyte rolling and firm adhesion. Proc Natl Acad Sci USA 97:11262-11267. 
9. Damiano ER, Westheider J, Tözeren A, Ley K. (1996). Variation in the velocity, deformation, and adhesion energy density of leukocytes rolling within venules. Circ Res 79:1122-1130.

10. Dembo M. (1994). On peeling an adherent cell from a surface. Lec Math Life Sci 24:51-77.

11. Finger EB, Bruehl RE, Bainton DF, Springer TA. (1996). A differential role for cell shape in neutrophil tethering and rolling on endothelial selectins under flow. J Immunol 157:5085-5096.

12. Fung YC. (1997). Biomechanics. New York: Springer Science \& Business Media.

13. Gillespie DT. (1977). Exact stochastic simulation of coupled chemical reactions. J Phys Chem 81:23402361.

14. Goldman AJ, Cox RG, Brenner H. (1967). Slow viscous motion of a sphere parallel to a plane wall-I. Motion through a quiescent fluid. Chem Eng Sci 22:637-651.

15. Goldman AJ, Cox RG, Brenner H. (1967). Slow viscous motion of a sphere parallel to a plane wall-II. Couette flow. Chem Eng Sci 22:653-660.

16. Goldsmith HL, Spain S. (1984). Margination of leukocytes in blood flow through small tubes. Microvasc Res 27:204-222.

17. Graf C, Barras JP. (1979). Rheological properties of human blood plasma-a comparison of measurements with three different viscometers. Cell Molec Life Sci 35:224-225.

18. Hammer DA, Apte SM. (1992). Simulation of cell rolling and adhesion on surfaces in shear flow: general results and analysis of selectin-mediated neutrophil adhesion. Biophys J 63:35-57.

19. Hochmuth RM. (2000). Micropipette aspiration of living cells. J Biomech 33:15-22.

20. Hogg RV, Tanis EA. (1997). Probability and Statistical Inference. Upper Saddle River, New Jersey, USA: Prentice-Hall.

21. House SD, Lipowsky HH. (1988). In vivo determination of the force of leukocyte-endothelium adhesion in the mesenteric microvasculature of the cat. Circ Res 63:658-668.

22. Jadhav S, Eggleton CD, Konstantopoulos K. (2005). A 3-D computational model predicts that cell deformation affects selectin-mediated leukocyte rolling. Biophys J 88:96-104.

23. Khismatullin DB, Truskey GA. (2005). Three-dimensional numerical simulation of receptor-mediated leukocyte adhesion to surfaces: effects of cell deformability and viscoelasticity. Phys Fluids 17:031505.1031505.21 .

24. Krasik EF, Hammer DA. (2004). A semianalytic model of leukocyte rolling. Biophys J 87:2919-2930.

25. Krasik EF, Yee KL, Hammer DA. (2006). Adhesive dynamics simulation of neutrophil arrest with deterministic activation. Biophys J 91:1145-1155.
26. Lawrence MB, Kansas GS, Kunkel EJ, Ley K. (1997). Threshold levels of fluid shear promote leukocyte adhesion through selectins (CD62L,P,E). J Cell Biol 136:717-727.

27. Lawrence MB, Springer TA. (1991). Leukocytes roll on a selectin at physiologic flow rates: distinction from and prerequisite for adhesion through integrins. Cell 65:859-873.

28. Lecca P, Priami C, Laudanna C, Constantin G. (2004). A BioSpi model of lymphocyte-endothelial interactions in inflamed brain venules. Pacific Symp Biocomput 9:521-532.

29. Li F, Erickson HP, James JA, Moore KL, Cummings RD, McEver RP. (1996). Visualization of P-selectin glycoprotein ligand-1 as a highly extended molecule and mapping of protein epitopes for monoclonal antibodies. Biol Chem 271:6342-6348.

30. Marshall BT, Sarangapani KK, Lou J, McEver RP, Zhu C. (2005). Force history dependence of receptorligand dissociation. Biophys J 88:1458-1466.

31. Marshall BT, Sarangapani KK, Wu J, Lawrence MB, McEver RP, Zhu C. (2006). Measuring molecular elasticity by atomic force microscope cantilever fluctuations. Biophys J 90:681-692.

32. Mehta P, Cummings RD, McEver RP. (1998). Affinity and kinetic analysis of P-selectin binding to P-selectin glycoprotein ligand-1. J Biol Chem 273:32506-32513.

33. Milner R. (1999). Communicating and Mobile Systems: The $\pi$-Calculus. Cambridge, UK: Cambridge University Press.

34. Moore KL, Patel KD, Bruehl RE, Fugang L, Johnson DA, Lichenstein HS, Cummings RD, Bainton DF, McEver RP. (1995). P-selectin glycoprotein ligand-1 mediates rolling of human neutrophils on P-selectin. $J$ Cell Biol 128:661-671.

35. Moore KL, Varki A, McEver RP. (1991). GMP-140 binds to a glycoprotein receptor on human neutrophils: evidence for a lectin-like interaction. J Cell Biol 112:491-499.

36. Park EYH, Smith MJ, Stropp ES, Snapp KR. DiVietro JA, Walker WF, Schmidtke DW, Diamond SL, Lawrence MB. (2002). Comparison of PSGL-1 microbead and neutrophil rolling: microvillus elongation stabilizes P-selectin bond clusters. Biophys $J$ 82:1835-1847.

37. Patel KD, Nollert MU, McEver RP. (1995). P-selectin must extend a sufficient length from the plasma membrane to mediate rolling of neutrophils. J. Cell Biol 131:1893-1902.

38. Priami C. (1995). Stochastic $\pi$-calculus. Computer J 38:578-589.

39. Ray N, Acton ST, Ley K. (2002). Tracking leukocytes in vivo with shape and size constrained active contours. IEEE Trans Med Imaging 21:1222-1235. 
40. Schmid-Schönbein GW. (1990). Leukocyte biophysics. An invited review. Cell Biophys 17:107-135.

41. Shao JY, Ting-Beall HP, Hochmuth RM. (1998). Static and dynamic lengths of neutrophil microvilli. Proc Natl Acad Sci USA 95:6797-6802.

42. Springer TA. (1990). Adhesion receptors of the immune system. Nature 346:425-434.

43. Tissot O, Pierres A, Foa C, Delaage M, Bongrad P. (1992). Motion of cells sedimenting on a solid surface in a laminar shear flow. Biophys J 61: 204-215.

44. Tözeren A, Ley K. (1992). How do selectins mediate leukocyte rolling in venules? Biophys J 63:700-709.

This paper was first published online on iFirst on 27 December 2008.
45. Yago T, Leppänen A, Qiu H, Marcus WD, Nollert MU, Zhu C, Cummings RD, McEver RP. (2002).

Distinct molecular and cellular contributions to stabilizing selectin-mediated rolling under flow. J Cell Biol 158:787-799

46. Yu Y, Shao JY. (2007). Simultaneous tether extraction contributes to neutrophil rolling stabilization: a model study. Biophys J 92:418-429.

47. Zipursky A, Bow E, Seshadri RS, Brown EJ. (1976). Leukocyte density and volume in normal subjects and in patients with acute lymphoblastic leukemia. Blood 48:361-371. 